\title{
The Exploration And Practice Of Course Examination Methods Reform On Linear Algebra
}

\author{
Ya Li He $\mathrm{H}^{1, \mathrm{a} *}$, Xiao Qiang Guo ${ }^{1, b}$ \\ ${ }^{1}$ Institute of Science, Hebei United University , No.46, Xinhua West Road, Tangshan, China \\ a 1067448792@qq.com, b122702030@qq.com,
}

Keywords: Linear Algebra; Examination methods; Reform; Diversified evaluation test ways.

\begin{abstract}
Based on deeply analysis on the current shortcomings and problems of linear algebra examination way, this paper further define the purpose and principles of evaluation way reform, Multiplicate examination forms were introduced in order to overall evaluation of students' comprehensive ability, and produced the concrete implementation plan. At the same time, this paper probes into the problems existing and effect in the use of the new examination way.
\end{abstract}

\section{Introduction}

Linear algebra is a branch of algebra mainly to deal with linear relationship. It is one of the three basic math course for all students in higher engineering subject. The last half of the 20th century, along with the endless progress and development of the science and technology of computer, the application of linear algebra has been extended to more and more new areas. The measure intended for large-scale complex problems at the moment is change a nonlinear problem into a linear in order to simplify the relationship between the variables. So large-scale calculation method of the linear algebra has become an important mathematical tools.

The characteristics of linear algebra are abstractness and dullness. It is usually arranged by three main knowledge composing of matrix, vector and the system of linear equations. The three main knowledge is closely related to each other, organic combined, crisscross, mutual penetration, explain to each other, Beginners often feel chaos and confusion, unable to achieve real sense of understanding. In order to make students understand and grasp the linear algebra and its application profoundly, Many mathematics education workers has also put in a lot of power to reform linear algebra course. However, the reform of curriculum system, teaching content and teaching method was more concerned in the curriculum reform and development, with respect to the manner of the examination reform was seldom mentioned. Examinations and texts are important parts of the teaching and learning process. They are basic means of testing and evaluating teachers' teaching quality and students' studying effect. But the exam for this course has always been consisted of a piece of paper by the end of the semester in assessment. Therefore, exploring a decent examination method and evaluation system, which can evaluate students' learning processes scientifically and can better reflect the teaching effect of the linear algebra courses should become a important part of the linear algebra teaching reform. Based on deeply analysis on the current shortcomings and problems of linear algebra examination way, this paper further define the purpose and principles of evaluation way reform, multiplicate examination forms were introduced in order to overall evaluation of students' comprehensive ability, and produced the concrete implementation plan. At the same time, this paper probes into the problems existing and effect in the use of the new examination way.

\section{Non-adaptive points of traditional assessment methods on linear algebra courses}

Closed book exam is rational as it is a traditional Chinese examine and evaluate method. This exam method asks students to remember some of the most basic knowledge, principles. It is necessary to strengthen the students' firm degree of mastery knowledge and test the proficiency. However, what the closed book exam emphasized is the evaluation function of exams, which is always reflected on judgments of the value of scores and has been extremely exaggerated. This can only make teachers 
teach for exams, while students study for exams. This kind of exam can only enhance one's test ability and weaken other abilities. The paper-type examination obviously can neither evaluate the students' learning process equitably, nor can it response to the teaching effect, for the feature of this course is focus on both theory and practice. Firstly, students will easily form the rote examination mode and just understand the knowledge ostensibly with the form of a written test. Secondly, the content of the examination is lack of practice. Numerical computation is a mathematical course that closely linked with computer use and very practical. Closed book exam is only limited on paper, while lacking the test towards the actual operating capacity of the students. Thirdly, from this method we can only obtain one-sided conclusion and limit the students' creative thinking, which make little significance to strengthen the teaching effect.

\section{Purposes and principles of assessment methods reform}

For any subject, the purpose of the exam is to test teaching process and learning effect. That means to test the realization of educational goals for short. As we mentioned earlier that, we can not get the result we want from the paper-type exam for the feature of this course is focus on both theory and practice. Generally, student should complete the migration after gain the knowledge, which means he has the ability to apply what he has learned. Then we may say that he has learned the knowledge and make it as his own. Thus, when he encounters a similar question in life, he will be able to identify it effectively and use knowledge to solve problems. Learn to grasp and apply the knowledge, enhance the scientific computing capacity, solve practical problems in the production and living are the real training goals of linear algebra. To do this, our reform should find a new exam method to test the teaching process and learning effect scientifically and impartially around this core. Therefore the author thinks that linear algebra exam method reform should obey the principles as follows: transform the paper-type exam into a wide range of comprehensive examination mode; make theoretical basic knowledge more combined to practice, pay attention to student's abilities of analyzing and solving; make comprehensive test of the students, including summative evaluation, process evaluation and development evaluation. We should make linear algebra exams both the process and effect of students study, and at the same time, test their level of knowledge gaining and practical ability; Thus enhance the overall quality and achieve the goals.

\section{Implement diversified assessment to fully evaluate student comprehensive capacity}

Diversified examination. It's a full range of evaluation implement to students, which especially against their abilities of learning, application and innovation etc. We'd better extend the examination process, expand the content of test, and strive to test learning effect more comprehensive and objective by establishing a comprehensive evaluation system. We tried a combination of open-book and closed book exam in linear algebra teaching, the total score includes $40 \%$ both of the open-book and closed book score, $10 \%$ for normal performance, and the remaining $10 \%$ for a short essay. The open-book part includes numerical experiments, synthesis report and small engineering application issues, while the closed book part includes basic concepts required on the syllabus, basic theory and commonly used algorithms, in order to exam students' mastery of basic knowledge and theoretical analysis and written calculation. Normal result is that the operations result, including three quarters of theory deducing operations and one quarter of practice topics. This exam system test student from various aspects, such as theoretical knowledge, mathematical model, algorithm design, programming, practical problem solving. They are so helpful to inquiry study and practice that anyone of these should not miss.

Analysis of the adaptability. Any part of the diversified examination will affect the composite score. It may be less objective, but do better than one-paper form. The closed book part guarantees the grasp of the basic theory, basic knowledge and common algorithms; Normal result plays the role of supervision and oversight of students' learning process; Experimental part of the open-book part test student ability of software applications and practical ability; Synthesis report enable students to understand the value and scope of the various algorithms; Engineering topics help 
students to master the ideas and methods to solve practical problems by linear algebra. Such a wide range of assessment methods can activate the students' initiative and creativity in the subject examination, and promote an overall improvement in the students' character development and subject ability and quality, effectively changing the drawbacks of the old assessment model. Therefore, this diversity examination method meets the characteristics of the course and teaching purposes of linear algebra.

Implementation methods. Closed book examination: A Traditional classical examination method, which presents very good result on examining students' mastery of basic theory. Assessment requirements: enable students to master basic concepts, algorithms and basic theory. Questions include Multiple-choice, fill in the blank, calculation problems, short answers and proofs etc.

Open-book examination: The numerical experiments section refers to the algorithm design and implementation of specific problem; Synthesis report aims at to make a comprehensive overview on part of the existing research results, research progress and application value, and future research directions by reading the relevant information; Engineering topics need student complete the whole process of "mathematical modeling $\rightarrow$ algorithm design $\rightarrow$ Programming $\rightarrow$ Analysis" by either written test or an essay; Leaving some time for the test and working in a team are both allowed. Exam emphasizes on the knowledge analyzing and problem-solving skills. We should make some empirical type and case type subjects closely linked to social practice and real life, in order to strengthen the value and mastery of the knowledge. Students have no pressure opening book and finding the answers and full play to their imagination in this exam, and finally draw the most realistic results without cheating.

Normal results: Normal results are mainly gained through normal operations, computer experiments and question answer results, which reflect students' learning attitude and learning process. It is also an extend of the class teaching or an important means to improve the quality of classroom teaching by controlling usual tests, works, sampling, questions and recording each student's classroom attendance.

Essay: We learn from the form of mathematical modeling competition, and divide students into several groups, let them use knowledge to solve simple questions in practice and write essays according to their own professions. Take general optimization problem and optimal value calculation for example, students find information, do researches in groups, and specify the tasks undertaken by students within groups to enable teachers to score. It mainly focuses on evaluating students' comprehensive quality.

\section{Implementation effect of assessment method reform}

Examination itself is the behavior of a teaching interaction and teacher-student interaction. Students 'academic assessment is a reaction of teachers' teaching effect, whose feedback information will bring inspirations to the next step of teachers' teaching behavior. Therefore, under the premise of ensuring the scientific nature and completeness and accuracy of the teaching content, we make diversified exams to extend the basic theory into social practice, operation ability, cooperation awareness and innovation capability, then convert them to the new knowledge. It is helpful to improve the education level, enhance the overall strength of the discipline and students' knowledge ability and overall quality.

Teaching part. Diversified assessment methods played a catalytic role in students' normal study. We divide the total score into several evaluation projects, intersperse assessments throughout the learning process, which make students pay more attention on study and concern every detail of it. Student' independent learning ability and utilization of classroom time are significantly improved.

Testing part. The percentage of basic knowledge assessment is decreasing in the total score, while the percentage of normal results and practical application of knowledge assessment increasing, which show the importance of learning attitude and practical operation skills. So the examination method of < linear algebra $>$ course is better adapted to the higher education teaching. The concept 
of "diversified assessment" and course evaluation settings has a good reference for all higher education programs.

Capacity-building part. Diversified assessment method covers assessments of mastery of the basics, knowledge integrating ability, problem-solving ability and level of reasoning and creative thinking. Thus, it is of great benefit to promote academic development and students' personality and overall quality.

Management part. Examination reform improved the students' interest in study, but at the same time increased the workload of teachers and difficulty of assessment management indirectly. Teachers' test counseling, test marking and exam design, homework correcting will correspondingly increase, which will bring new pressures to them. In addition, this examination is still in the pilot phase, particularly the open book part, there is still a problem lurking. For example, we don't know how to avoid bringing large wide range questions that can not be done in the specified time to students, and how to choose the typical topics of moderate difficulty and relate to students' professional. That is the key to this link, and also our further study topic.

\section{References}

[1] Xu Jing. Discussion on the examination methods reform based on Capacity-building, J. Heilongjiang Researches on Higher Education, No.10, 2006. 111-112.

[2] Liu Suyi, Xue Yong. Exploration and practice of the University examination methods reform, J. China Electric Power Education, No.2, 2009,57-58.

[3] Zhao Dongyang, Zhang Xuhui. Discussion on examination reform in colleges and universities based on the ability evaluation, Journal of Shanxi J. University of Finance and Economics(Higher Education Edition), No.3, 2011.80-86.

[4] Yan hongmei,jing xin,liu dan, The exploration of course examination methods reform on linear algebra, J. Times Educational ,No.10,2011, 44-45.

[5] Wang xingfa, Zheng ying, Several ideas about linear algebra teaching reform in application-oriented college and university, J. Course Education Research No.3, 2014 , 149.

[6] Ma changfeng, Lin weichuan, Modern numerical calculation method, Beijing Sciences Press, 2013.

[7] Sun caiyun, Disadvantages and reform measures of curriculum examination in University Mathematics, J. Guangxi Education, No.4, 2010, 83-85.

[8] Zhang li, Analyses the reform of actual examine system in university, J. Journal of Jiamusi Education Institute, No.6, 2010,152-153. 